\title{
Circulating unmethylated insulin DNA as a potential non-invasive biomarker of beta cell death in type 1 Diabetes: a review and future prospect
}

\author{
Kuo Zhang, Guigao Lin, Yanxi Han, Jiehong Xie and Jinming Li
}

\begin{abstract}
Background: The early detection of type 1 diabetes (T1D) largely depends on a reliable approach to monitor $\beta$ cell loss. An effective way to evaluate the decline of $\beta$ cell mass would allow early preventative intervention to preserve insulin secretion.

Main body: Recent progress in the development of novel biomarkers, based on tissue-specific methylation patterns, has inspired relevant studies in T1D. In this review, we focus on the application of circulating $\beta$ cell-derived unmethylated insulin (INS) DNA. Circulating $\beta$ cell-derived unmethylated INS DNA has a potential clinical value for the early detection of T1D, surveillance of islet transplantation rejection, and evaluation of response to therapy. Utilizing differentiated methylation patterns in different organs and employing a wide variety of molecular technologies also provide insights into the interrogation of biomarkers in other diseases with massive tissue-specific cell loss.
\end{abstract}

Conclusion: Circulating unmethylated INS DNA is a promising molecular biomarker for the early detection of T1D.

Keywords: Type 1 diabetes, Early detection, Cell-free DNA, Unmethylated insulin DNA, Molecular biomarkers

\section{Background}

Type 1 diabetes (T1D) is a complex disorder characterized by autoimmune destruction of $\beta$ cell mass and hyperglycemia [1]. The loss of $\beta$ cells may occur long before T1D can be diagnosed, given that T1D can only be diagnosed once approximately $65 \%$ of $\beta$ cells have been killed $[2,3]$. Therefore, early detection of $\beta$ cell depletion may provide prompt therapeutic approaches or preventative interventions for type 1 diabetes mellitus.

Multiple genetic and environmental factors are involved in the onset of T1D. Therefore, a wide variety of biomarkers including the levels of insulin, proinsulin, and C-peptide [4], as well as circulating microRNAs [5] and HLA genotypes [6] have been investigated for the screening of high-risk individuals. However, none of these biomarkers has been effective, as they are only

\footnotetext{
* Correspondence: jmli@nccl.org.cn

National Center for Clinical Laboratories, Beijing Hospital, National Center of Gerontology, No.1 Dahua Road, Dong Dan, Beijing 100730, People's Republic of China
}

(c) The Author(s). 2017 Open Access This article is distributed under the terms of the Creative Commons Attribution 4.0 International License (http://creativecommons.org/licenses/by/4.0/), which permits unrestricted use, distribution, and reproduction in any medium, provided you give appropriate credit to the original author(s) and the source, provide a link to the Creative Commons license, and indicate if changes were made. The Creative Commons Public Domain Dedication waiver (http://creativecommons.org/publicdomain/zero/1.0/) applies to the data made available in this article, unless otherwise stated.

present after the insulin secretion ability has been significantly compromised, limiting their use in identifying ongoing $\beta$ cell loss. Autoantibodies targeting antigens such as insulin; glutamic acid decarboxylase; protein phosphatase-like IA-2; zinc transporter-8 [7]; cytokines such as IL-1 $\beta$, TNF, IFN- $\gamma$, and IFN family members; and $\mathrm{T}$ cell signatures [8], as well as the frequently used glucose levels, have been associated with $\beta$ cell dysfunction [9]. These biomarkers of immune activation and $\beta$ cell function can be used to evaluate the risk of developing T1D. However, they are limited in their ability to detect the loss of $\beta$ cell mass and are more useful to monitor T1D progression [9]. Therefore, the lack of a method to directly detect $\beta$ cell loss limits the possibility of detecting T1D within the potential therapeutic window period. Additionally, our understanding of the kinetics of T1D progression is limited because we do not have methods that directly measure the primary pathologic process, $\beta$ cell death. 
Promoter methylation controls tissue-specific gene expression. There has been an upsurge of interest in the exploration of circulating methylation markers as a diagnostic tool for cancer [10]. Extensively investigated biomarkers in this area include the SEPT9 methylation blood test for colorectal cancer, which has been approved by the Food and Drug Administration (FDA) (http://www.accessdata.fda.gov/ cdrh_docs/pdf13/p130001a.pdf). Progress in this field has inspired the development of novel methylation-based molecular biomarkers for other diseases with or without aberrations in DNA methylation patterns. This review summarizes recent findings in the development of $\beta$ cell-derived circulating unmethylated insulin (INS) DNA for early detection of T1D.

\section{Potential of circulating unmethylated INS DNA as a diagnostic tool for T1D}

Cell-free DNA (cfDNA) is a noninvasive "liquid biopsy" because changes in cfDNA can reflect physiological and pathological conditions [11]. Efforts have been made to identify tumor-specific cfDNA as reviewed by Schwarzenbach et al. [11]. Recently, the combination of cfDNA and cell-specific methylation patterns have provided a means by which $\beta$ cell-specific circulating DNA can be detected. DNA methylation is an epigenetic event that modulates tissue-specific and developmentally regulated gene expression [12]. In this process, a methyl group is added to the $5^{\prime}$-position of cytosine of a CpG (cytosine-guanine) site. Tissue-specific methylation patterns make it possible to use differentially methylated DNA as a tool for diagnostic purposes. For example, the INS gene is uniquely unmethylated in the $\beta$ cells of pancreatic islets $[5,13]$. During the progression of T1D, $\beta$ cells are destroyed by cytotoxic $\mathrm{T}$ lymphocytes; unmethylated INS DNA molecules are shed into the bloodstream and they become detectable (Fig. 1). This process allows the specific detection of $\beta$ cell death in a minimally invasive manner, because the target sequences are specifically derived from $\beta$ cells, not from other tissues such as blood cells, which contribute to the majority of cfDNA [11].

Based on the theory that each cell type in the body carries unique methylation marks, a number of studies have reported the specific methylation profile of insulinsecreting $\beta$ cells in mouse or in human (Table 1) [13-16]. The most extensively investigated target of cell-specific DNA methylation is the INS gene. Due to the fact that the mouse genome consists of two insulin genes (Ins1 and Ins2), both genes were examined for $\beta$ cell-specific CpG sites $[13,14,16]$. Interestingly, four CpG sites in exon 2 of Ins 2 were revealed to be in a tissue-specific methylation pattern [14]. Comparing the levels of unmethylated DNA from islets with those from different tissues such as the lung, kidney, heart, blood, liver, brain, fat, and thymus, $\beta$ cells were demonstrated to be the primary source of unmethylated INS DNA $[13,17,18]$. Sequencing of DNA from INS-positive $\beta$ cells and INS-negative cells in mice revealed a 45-fold increase in unmethylated DNA in the insulin-positive cells [13], and the same trend was observed in human tissues [13, 14, 16]. The CpG sites were concentrated on the promoter region of the INS gene, and $\beta$ cells showed an unmethylated INS status compared to cells from other tissues in human [15].
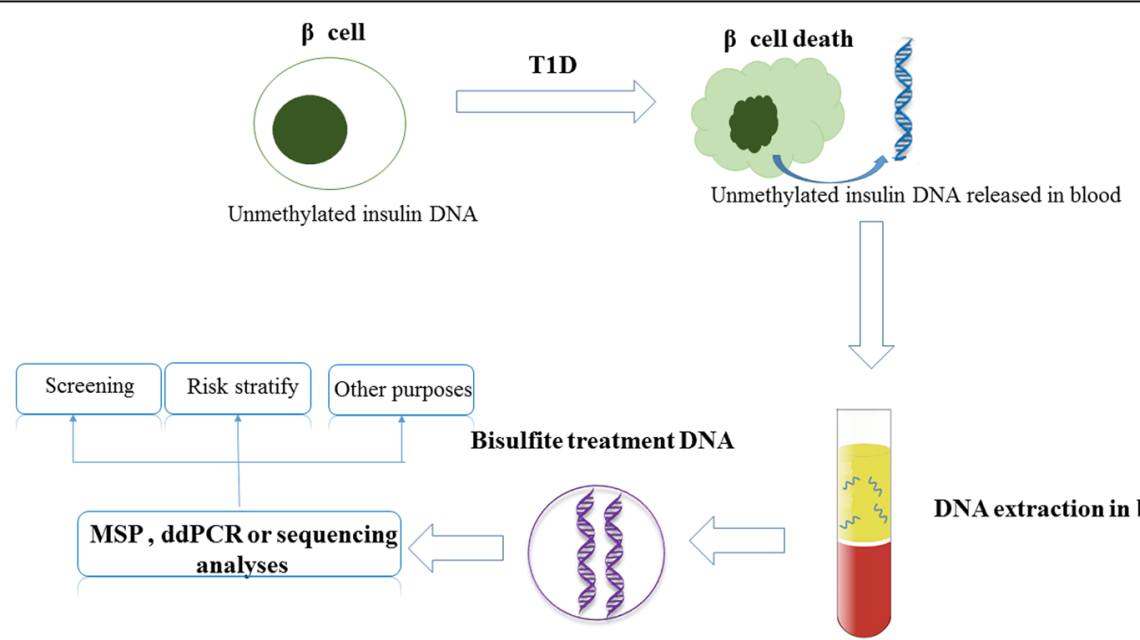

DNA extraction in blood

Fig. 1 Circulating unmethylated INS DNA can be used to trace $\beta$ cell death. The CpG sites of the INS gene are predominantly unmethylated in $\beta$ cells, which is vastly different from those in other tissues. Autoimmune destruction conducted by immune cells can lead to direct damage of $\beta$ cells. Unmethylated INS DNA is then released into the circulation. cfDNA can be extracted from blood samples. Following bisulfite treatment of cfDNA, unmethylated INS DNA molecules can be detected and quantified by a number of technologies including methylation-Specific PCR(MSP), droplet digital PCR $(d d P C R)$, and sequencing. Apart from the early diagnosis of T1D, the detection of circulating unmethylated INS DNA has the potential for monitoring transplantation rejection and response to therapy 
Table 1 Unmethylated loci in $\beta$ cells identified by studies

\begin{tabular}{lll}
\hline Gene (source) & $\begin{array}{l}\text { Position relative to the transcription } \\
\text { start site }\end{array}$ & Reference \\
\hline Ins1 (mouse) & +177 & 13 \\
Ins2 (mouse) & $+190,+310,+337,+340$ & 14 \\
Ins2 (mouse) & $-414,-182,-171$ & 16 \\
INS (human) & $-357,-206,-135,-69,-19$ & 15 \\
INS (human) & $-357,-345,-234,-206$, & 16 \\
& $-180,-135,-102,-69,-19$ & \\
\hline
\end{tabular}

\section{Use of circulating unmethylated INS DNA to screen for T1D}

The exploration of unmethylated CpG sites has promoted the development of methylation-specific primers or probes to assay $\beta$ cell-released DNA molecules in the blood. Several groups have shown that circulating unmethylated INS DNA is a promising indicator of $\beta$ cell death in both mouse models and humans. Akirav and colleagues [13] identified that circulating unmethylated DNA from $\beta$ cells can be used to detect $\beta$ cell death. In a mouse model in which $\beta$ cells were acutely injured (BALB/c mice treated with high-dose streptozotocin), the demethylation index ( $2^{\text {(methylated cycle number) - (demethy- }}$ lated cycle number), representing the relative abundance of unmethylated DNA), was increased 2.6-fold and 3.8-fold 8 and $24 \mathrm{~h}$ after treatment, respectively. In non-obese diabetic (NOD) autoimmune mice, which simulate the chronic onset of T1D, the median demethylation index increased 21 -fold prior to the decrease in insulin levels. In this study, a negative correlation was found between pancreatic insulin content and the demethylation index [13]. The results were consistent with those of other studies, in which significant elevated levels of circulating unmethylated INS DNA were detected well before the onset of hyperglycemia in high-/ low-dose streptozotocin-administrated NOD/SCID mice and in NOD mice, respectively $[14,15,17]$.

A higher level of unmethylated INS DNA was observed in five patients with new-onset T1D [13], and Lebastchi and colleagues further confirmed these results in a larger cohort study of 43 patients with new-onset T1D [19]. A follow-up study included a group of people with a "high risk" of developing T1D [20]. According to the study, relatives of T1D patients with two or more biochemical autoantibodies, abnormal glucose tolerance test results and normal HbA1c levels were considered as at-risk subjects [20]. This result revealed that the levels of unmethylated INS DNA were significantly higher in patients with recent T1D onset and at-risk individuals compared with those in non-diabetic controls [20]. The area under the receiver operating characteristic (ROC) curve was 0.834 , allowing discrimination between T1D patients and health controls with a sensitivity of $38 \%$ and a specificity of $95 \%$. The ability to identify at-risk subjects from non-diabetic control subjects was further enhanced, with the area of the ROC analysis being 0.897 with $58 \%$ sensitivity [20]. This was the first study to screen at-risk human subjects, the population that will benefit most from the early detection of T1D in a clinical setting. Furthermore, this was also the first time that ROC curve analyses were used to determine the diagnostic performance of unmethylated INS DNA in monitoring ongoing $\beta$ cell death. A subsequent retrospective longitudinal study was conducted by the same group, in which an at-risk population was further divided into progressors (who developed T1D after a 3- to 4-year period) and nonprogressors (who did not develop T1D over a similar time interval) [21]. Comparison with healthy controls showed that progressors had a significantly increased unmethylation ratio (the levels of unmethylated INS DNA/the levels of methylated INS DNA). Furthermore, a strong inverse relationship between increased unmethylation ratio and ISR AUC (the area under the insulin secretion rate curve, representing the total insulin secreted in a 2-h test) was observed in progressors. More importantly, analysis of a separate group of "high-risk" individuals (shown by the presence of at least two autoantibodies and dysglycemia or impaired glucose tolerance) revealed that higher levels of unmethylated INS DNA can be measured, even when compared to the progressors and nonprogressors, indicating the potential of circulating unmethylated INS DNA to stratify the risk of T1D.

It is important to review several recently published results that present novel ideas for the investigation of circulating unmethylated INS DNA. Fisher et al. [22] determined the absolute levels of both unmethylated and methylated INS DNA in human using droplet digital PCR (ddPCR). Surprisingly, the levels of unmethylated INS DNA and methylated INS DNA were significantly increased at T1D onset. At 8 weeks post-onset, methylated INS DNA levels remained elevated while unmethylated INS DNA levels fell, and both parameters returned to control levels 1 year post-onset [22]. These observations have raised three questions: (1) How do the levels of both unmethylated and methylated INS DNA change in subjects with high risk of T1D prior to diagnosis? (2) How do the absolute levels of both parameters contribute to the demethylation index (as described in previous studies) to indicate the relative abundance of unmethylated DNA?; and (3) How does the autoimmune destruction of $\beta$ cells, and other relevant cells, contribute to longitudinal changes in both parameters? Interestingly, during the progression of T1D in the NOD mouse model, the levels of methylated INS DNA in $\beta$ cells can increase as a direct result of inflammatory destruction [23]. However, whether this increase contributes to the elevated levels of circulating methylated INS DNA requires further investigation. 
Lehmann-Werman et al. [18] showed that the detection of several adjacent CpG sites could provide a better signal-to-noise ratio when measuring the levels of unmethylated circulating INS DNA. This concept is based on the dynamic nature of cells regulating tissue-specific methylation. In other words, the methylation status of a tissue may undergo stochastic changes due to aging (epigenetic drift), which can be enhanced by genetic and environmental factors [24-27]. This concept was consistent with previous results, showing methylated $\mathrm{CpGs}$ of the INS gene from $\beta$ cells and unmethylated CpGs from other tissues [13-17]. By screening the combined methylation status of six CpG sites of the INS promoter ("unmethylated" or "methylated" defined by all six CpGs showing at least $80 \%$ similarity with the target sequences), the author significantly improved the sensitivity and the specificity of the assay. The results revealed that the levels of $\beta$ cellderived DNA were significantly higher in recently diagnosed T1D patients compared with those in health controls (10 vs. $175-1450$ genomes $/ \mathrm{mL}, P<0.0001$ ) [18].

\section{Major strengths of using methylation pattern to screen for T1D}

The application of circulating INS DNA has a number of attractive features. First, the unique methylation pattern of the INS gene in $\beta$ cells makes this approach specific and allows $\beta$ cell destruction to be distinguished from the cell death of other tissues. This avoids the problems observed with cfDNA methylation-based biomarkers, whereby the aberrantly methylated loci in one malignancy type may also occur in other malignancies or diseases. Additionally, aberrant gene expression in the circulation may directly result from the effects of the tumor on blood cells, as white blood cells contribute the majority of cfDNA molecules [28]. Most importantly, DNA aberrations alone do not provide information pertaining to the exact source of these molecules.

Second, the use of blood for the assay is well suited for diagnostic purposes. As the most frequently explored starting material, obtaining blood can be steadily repeated and minimally invasive. This means that the assay is easily accessible to all subjects, including patients and at-risk individuals. Another major advantage is the inherent stability of cell-free DNA. Compared to other biomarkers such as microRNA and protein-based markers, DNA molecules are relatively stable. In the circulation, DNA molecules are predominantly found in the form of nucleosomes that either circulate as nucleoprotein complexes or adsorb to the surface of blood cells [29]. Furthermore, it is estimated that the half-life of unmethylated INS DNA is around $2 \mathrm{~h}$ [21], which means that the circulating levels of unmethylated INS DNA provide the opportunity to obtain real-time information of $\beta$ cell mass loss in a noninvasive manner.
Finally, the measurement of circulating $\beta$ cell-released DNA can be performed with a wide range of PCR-based molecular approaches, including methylation-specific real-time PCR [13-15, 17, 19], ddPCR [20-22], and sequencing [18]. The presence of tissue-specific methylation patterns makes it easier to develop methylation-specific methodologies. The rapid development of molecular technologies allows measurements of $\beta$ cell-derived DNA to be identified using a small amount of starting material. For instance, a SYBR Green-based methylation-specific PCR can detect as few as 10 copies of unmethylated INS DNA circulating within genomic DNA with a coefficient of variation from 21.64 to $38.72 \%$ [14, 15]. Furthermore, the use of TaqMan PCR enhanced the discriminatory capability of methylation-specific PCR with relatively high signal-to-noise ratio, linear assay output, and simultaneous detection of methylated and unmethylated INS DNA in a single PCR mix [17]. It is of note that ddPCR, which enables direct quantitation of differentially methylated DNA species in serum without the need for normalization, has been widely used in the research of $\beta$ cell-released DNA, one of which obtained 1.87 and $1.37 \%$ as the coefficients of variation from two sample sets [20-22] The multiplexed ddPCR developed by Usmani-Brown et al. allowed the detection of about 0.7 copies $/ \mu \mathrm{L}$ of unmethylated INS DNA targets [20]. Furthermore, Lehmann-Werman et al. [18] used sequencing to identify unmethylated INS DNA with remarkably enhanced sensitivity and specificity, as well as low cost (about $\$ 10$ each sample), making the simultaneous detection of several adjacent CpGs a reality. We believe that sequencing technologies will be increasingly important in upcoming studies.

\section{Future prospects}

In addition to the early detection of T1D and screening of at-risk subjects, circulating unmethylated DNA could be of clinical value for other purposes such as monitoring transplantation rejection and response to therapy. In islet transplantation cases, demethylated INS DNA could be detected from day 1 to day 14 post-transplantation [15]. Another study, focusing on a shorter period of time after transplantation, found that $\beta$ cell death peaked by 360 min post-transplantation in four autologous islet recipients [21]. Lebastchi et al. [19] provided additional insight into the effects of medication on $\beta$ cell death. Compared to placebo-treated controls, a dramatic decline in the relative level of unmethylated INS DNA (Ct value of methylated DNA - Ct value of unmethylated DNA) was observed in patients after 1 year of treatment with teplizumab, indicative of a reduced level of $\beta$ cell destruction as a result of immune therapy [19].

A recent report described the use of the amylin gene, which is highly expressed in $\beta$ cells with unique unmethylated patterns in the coding region, in the identification of $\beta$ 
cell loss [30]. The ROC analysis showed an AUC of 0.866 to discriminate subjects with recent onset of T1D from healthy controls [30]. These results raise the possibility that there are other genes harboring $\beta$ cell-specific methylation patterns. We believe that with technological advances, more target genes of interest can be explored and readily combined into panels to optimize the sensitivity and specificity of these assays. Another recent study reported a negative relation between the onset of gestational diabetes mellitus (GDM) and $\beta$ cell loss by using the detection of unmethylated INS DNA [31]. Interestingly, the levels of unmethylated INS DNA were significantly decreased in women with GDM comparing to women with normal pregnancy, women at postpartum, and non-pregnant women [31]. The study told us that the detection of unmethylated INS DNA may provide more detailed information about the natural history and heterogeneity of T1D, which is crucial to illustrate the etiology of T1D [32].

The small proportion of $\beta$ cell-released DNA within the background of circulating genomic DNA poses a technical challenge. Recently developed high-throughput molecular techniques with improved accuracy, such as multiplex ddPCR and next-generation sequencing (NGS), are anticipated to bring major improvements in this field. The ability to accurately perform low-level absolute quantification without the need of calibration makes ddPCR a popular technology for molecular diagnostics [33], while multiplex ddPCR enables the simultaneous quantification of more than five targets [34]. Sequencing has been applied in ongoing studies to overcome the issue of conventional methylation-specific PCR, which has high background signals resulting from nonprogrammed methylation, or demethylation, of CpG sites [18]. Using Illumina Miseq sequencing, the methylation status of four to nine CpG sites can be defined in a single reaction [18]. Another novel approach is genome-wide bisulfite sequencing. Using this approach, Sun et al. [28] produced a "tissue map" by identifying the relative proportions of DNA released from multiple tissue origins in the plasma of pregnant women, transplant recipients, and patients suffering from hepatocellular carcinoma. Such approaches will facilitate research into, and the development of, genome-wide tissue-specific methylation profiles. Furthermore, these studies are likely to yield advances in the development of footprints for a wide variety of cell types with specific epigenetic signatures $[35,36]$ and in other areas including finding the origin of forensic samples [37] and archeology researches [38].

\section{Conclusions}

The studies discussed above provided evidence that circulating unmethylated INS DNA can be a potential noninvasive biomarker of $\beta$ cell mass loss in T1D. Besides the early detection, this approach may also aid risk stratification, disease surveillance, and treatment response assessment in T1D. The feasibility of serial sampling makes the generation of a dynamic profile of $\beta$ cell mass destruction a reality. In addition, these studies offer new insights for the generation of novel biomarkers based on tissue-specific methylation patterns in cfDNA.

On the other hand, analyses of $\beta$ cell-derived unmethylated DNA in T1D are still in the early stages. A review of these studies reveals two major limitations that will need to be addressed in the coming years. One limitation is the relatively small sample size used in these studies, yet prospective and screening assessments for the diagnostic performance of circulating INS DNA remain warranted. Another concern is the inconsistent results obtained in the studies. The reasons for inconsistent results could be heterogeneous, including the use of different techniques with different sensitivities and differences in the target populations of study. These discrepancies can be addressed through the development of standardized processing protocols, which would allow comparisons between groups.

\section{Abbreviations \\ cfDNA: Cell-free DNA; ddPCR: Droplet digital PCR; INS: Insulin; ROC: Receiver operating characteristic; T1D: Type 1 diabetes}

\section{Acknowledgements}

This work was supported by the Special Fund for Health-scientific Research in the Public Interest from National Population and Family Planning Commission of the PR China (no. 201402018).

\section{Funding \\ Not applicable}

Availability of data and materials

Not applicable

Authors' contributions

All authors contributed to the writing of the review and approved the final manuscript.

Competing interests

The authors declare that they have no competing interests.

Consent for publication

Not applicable

Ethics approval and consent to participate

Not applicable.

\section{Publisher's Note}

Springer Nature remains neutral with regard to jurisdictional claims in published maps and institutional affiliations.

Received: 6 September 2016 Accepted: 14 April 2017

Published online: 26 April 2017

\section{References}

1. Bluestone JA, Herold K, Eisenbarth G. Genetics, pathogenesis and clinical interventions in type 1 diabetes. Nature. 2010;464:1293-300.

2. Meier JJ, Breuer TG, Bonadonna RC, Tannapfel A, Uhl W, Schmidt WE, et al. Pancreatic diabetes manifests when beta cell area declines by approximately 65\% in humans. Diabetologia. 2012;55:1346-54. 
3. Cnop M, Welsh N, Jonas JC, Jörns A, Lenzen S, Eizirik DL. Mechanisms of pancreatic beta-cell death in type 1 and type 2 diabetes: many differences, few similarities. Diabetes. 2005;54 Suppl 2:S97-107.

4. Ludvigsson J, Heding L. Abnormal proinsulin/C-peptide ratio in juvenile diabetes. Acta Diabetol Lat. 1982;19:351-8.

5. Syed F, Evans-molina C. Nucleic acid biomarkers of $\beta$ cell stress and death in type 1 diabetes. Curr Opin Endocrinol Diabetes Obes. 2016;23:312-7.

6. Pociot F, Lernmark $\AA$. Genetic risk factors for type 1 diabetes. Lancet. 2016;387:2331-9.

7. Lampasona V, Liberati D. Islet autoantibodies. Curr Diab Rep. 2016;16:53.

8. Pesenacker AM, Wang AY, Singh A, Gillies J, Kim Y, Piccirillo CA, et al. A regulatory $T$-cell gene signature is a specific and sensitive biomarker to identify children with new-onset type 1 diabetes. Diabetes. 2016;65:1031-9.

9. Sosenko JM. Staging the progression to type 1 diabetes with pre diagnostic markers. Curr Opin Endocrinol Diabetes Obes. 2016;23:297-305.

10. Warton K, Mahon KL, Samimi G. Methylated circulating tumor DNA in blood: power in cancer prognosis and response. Endocr Relat Cancer. 2016;23:R157-71.

11. Schwarzenbach H, Hoon DS, Pantel K. Cell-free nucleic acids as biomarkers in cancer patients. Nat Rev Cancer. 2011;11:426-37.

12. Robertson KD. DNA methylation and human disease. Nat Rev Genet. 2005;6:597-610.

13. Akirav EM, Lebastchi J, Galvan EM, Henegariu O, Akirav M, Ablamunits V, et al. Detection of $\beta$ cell death in diabetes using differentially methylated circulating DNA. Proc Natl Acad Sci U S A. 2011;108:19018-23.

14. Husseiny MI, Kuroda A, Kaye AN, Nair I, Kandeel F, Ferreri K. Development of a quantitative methylation-specific polymerase chain reaction method for monitoring beta cell death in type 1 diabetes. PLoS One. 2012;7:e47942.

15. Husseiny MI, Kaye A, Zebadua E, Kandeel F, Ferreri K. Tissue-specific methylation of human insulin gene and PCR assay for monitoring beta cell death. PLoS One. 2014;9:e94591.

16. Kuroda A, Rauch TA, Todorov I, Ku HT, Al-Abdullah IH, Kandeel F, et al. Insulin gene expression is regulated by DNA methylation. PLoS One. 2009:4:e6953.

17. Fisher MM, Perez Chumbiauca CN, Mather KJ, Mirmira RG, Tersey SA. Detection of islet $\beta$ cell death in vivo by multiplex PCR analysis of differentially methylated DNA. Endocrinology. 2013;154:3476-81.

18. Lehmann-Werman R, Neiman D, Zemmour H, Moss J, Magenheim J, Vaknin-Dembinsky A. Identification of tissue-specific cell death using methylation patterns of circulating DNA. Proc Natl Acad Sci U S A. 2016:113:E1826-1834

19. Lebastchi J, Deng S, Lebastchi AH, Beshar I, Gitelman S, Willi S, Gottlieb P, Akirav EM, Bluestone JA, Herold KC, et al. Immune therapy and $\beta$ cell death in type 1 diabetes. Diabetes. 2013;62:1676-80.

20. Usmani-Brown S, Lebastchi J, Steck AK, Beam C, Herold KC, Ledizet M. Analysis of $\beta$ cell death in type 1 diabetes by droplet digital PCR. Endocrinology. 2014;155:3694-8.

21. Herold KC, Usmani-Brown S, Ghazi T, Lebastchi J, Beam CA, Bellin MD, et al. $\beta$ cell death and dysfunction during type 1 diabetes development in at-risk individuals. J Clin Invest. 2015;125:1163-73.

22. Fisher MM, Watkins RA, Blum J, Evans-Molina C, Chalasani N, DiMeglio LA, et al. Elevations in circulating methylated and unmethylated preproinsulin DNA in new-onset type 1 diabetes. Diabetes. 2015;64:3867-72.

23. Rui J, Deng S, Lebastchi J, Clark PL, Usmani-Brown S, Herold KC. Methylation of insulin DNA in response to proinflammatory cytokines during the progression of autoimmune diabetes in NOD mice. Diabetologia. 2016;59:1021-9.

24. Feil R, Fraga MF. Epigenetics and the environment: emerging patterns and implications. Nat Rev Genet. 2012;13:97-109.

25. Christensen BC, Houseman EA, Marsit CJ, Zheng S, Wrensch MR, Wiemels JL, et al. Aging and environmental exposures alter tissue-specific DNA methylation dependent upon CpG island context. PLoS Genet. 2009;5:e1000602.

26. Shah S, McRae AF, Marioni RE, Harris SE, Gibson J, Henders AK, et al. Genetic and environmental exposures constrain epigenetic drift over the human life course. Genome Res. 2014;24:1725-33.

27. Zheng SC, Widschwendter M, Teschendorff AE. Epigenetic drift, epigenetic clocks and cancer risk. Epigenomics. 2016;8:705-19.

28. Sun $\mathrm{K}$, Jiang $\mathrm{P}$, Chan $\mathrm{KC}$, Wong J, Cheng YK, Liang RH, et al. Plasma DNA tissue mapping by genome-wide methylation sequencing for noninvasive prenatal, cancer, and transplantation assessments. Proc Natl Acad Sci U S A. 2015;112:E5503-12.

29. Laktionov PP, Tamkovich SN, Rykova EY, Bryzgunova OE, Starikov AV Kuznetsova NP, et al. Cell-surface-bound nucleic acids: free and cell-surface-bound nucleic acids in blood of healthy donors and breast cancer patients. Ann N Y Acad Sci. 2004;1022:221-7.

30. Olsen JA, Kenna LA, Spelios MG, Hessner MJ, Akirav EM. Circulating differentially methylated amylin DNA as biomarker of $\beta$ cell loss in type 1 diabetes. PLoS One. 2016;11:e0152662.

31. Kenna LA, Olsen JA, Spelios MG, Radin MS, Akirav EM. $\beta$-Cell death is decreased in women with gestational diabetes mellitus. Diabetol Metab Syndr. 2016;8:60-5.

32. Weir GC. Islet-cell biology in 2015: understanding secretion, ageing and death in $\beta$ cells. Nat Rev Endocrinol. 2016;12(2):72-4.

33. Huggett JF, Cowen S, Foy CA. Considerations for digital PCR as an accurate molecular diagnostic tool. Clin Chem. 2015;61:79-88

34. Didelot A, Kotsopoulos SK, Lupo A, Pekin D, Li X, Atochin I, et al. Multiplex picoliter-droplet digital PCR for quantitative assessment of DNA integrity in clinical samples. Clin Chem. 2013:59:815-23.

35. Grunau C, Hindermann W, Rosenthal A. Large-scale methylation analysis of human genomic DNA reveals tissue-specific differences between the methylation profiles of genes and pseudogenes. Hum Mol Genet. 2000;9:2651-63.

36. Ghosh S, Yates AJ, Frühwald MC, Miecznikowski JC, Plass C, Smiraglia D. Tissue specific DNA methylation of CpG islands in normal human adult somatic tissues distinguishes neural from non-neural tissues. Epigenetics. 2010;5:527-38.

37. Antunes J, Balamurugan K, Duncan G, McCord B. Tissue-specific DNA methylation patterns in forensic samples detected by Pyrosequencing ${ }^{\oplus}$. Methods Mol Biol. 2015:1315:397-409.

38. Pedersen JS, Valen E, Velazquez AM, Parker BJ, Rasmussen M, Lindgreen S, et al. Genome-wide nucleosome map and cytosine methylation levels of an ancient human genome. Genome Res. 2014;24:454-66.

\section{Submit your next manuscript to BioMed Central and we will help you at every step:}

- We accept pre-submission inquiries

- Our selector tool helps you to find the most relevant journal

- We provide round the clock customer support

- Convenient online submission

- Thorough peer review

- Inclusion in PubMed and all major indexing services

- Maximum visibility for your research

Submit your manuscript at www.biomedcentral.com/submit

) Biomed Central 